\title{
Overcoming Practical Barriers in Reconditioning Li-Polymer Batteries
}

\author{
IOANA-ALINA CIOBOTARU ${ }^{1}$, FLORIN-MIHAI BENGA ${ }^{1,2}$, IRINA-ELENA CIOBOTARU ${ }^{3}$, \\ DANUT-IONEL VAIREANU, ${ }^{1, *}$ \\ ${ }^{1}$ University Politehnica of Bucharest, Faculty of Applied Chemistry and Materials Science, 1-7 Polizu Str., 011061, \\ Bucharest, Romania \\ ${ }^{2}$ National Institute of Metrology, Physical Chemistry Laboratory, 11 Vitan-Barzesti, 042122, Bucharest, Romania \\ ${ }^{3}$ National Institute for Research and Development in Environmental Protection, 294 Splaiul Independentei, 060031, \\ Bucharest, Romania
}

\begin{abstract}
In this paper, two case studies regarding the application of a reconditioning procedure of aged lithium-polymer batteries used to power a notebook and a tablet are presented. The parameters measured in the evaluating the performance of the reconditioned rechargeable batteries are the charging/discharging capacity and the internal resistance. The results obtained indicate a high degree of reconditioning of the investigated batteries, expressed as a reconditioning coefficient, calculated on the basis of the measured nominal capacities after applying the reconditioning procedure with respect to the initial one.
\end{abstract}

Keywords: Li-Polymer, batteries, reconditioning procedure, reconditioning coefficient

\section{Introduction}

The progress in battery enabled their use in different applications in various domains. New energy devices were investigated and developed in order to provide for the increasing energy demands. The consumption of batteries increased significantly in the last decade, and, subsequently, the quantity of generated wastes. The improper disposal of aged and discharged batteries may cause severe environmental issues and have drawn the attention towards the development and the use of other more environmentally friendly batteries. Following this trend, the development and use of secondary (rechargeable) batteries has known an increase in the last decades. Among secondary batteries, a special interest is granted to lithium batteries (lithium-ion and lithium-polymer batteries) due to their high energy density and long lifetime. Lithium-polymer batteries tend to be more frequently used as they may be adapted to various forms required for electronic devices, are safer compared to lithium-ion batteries and have high energy density and high values of C-Rate [1-6].

The number of charging/discharging cycles is, however, limited mainly by the mode of exploiting of the battery during its lifetime. Recycling of spent batteries is an appealing alternative and various attempts have been made in this purpose; however, these methods focus on the recovery of useful elements and less on the restoration of the battery's capacity [7, 8]. Our previous work on lithiumpolymer batteries shows a reconditioning method employing consecutive controlled charging/ discharging steps that enable the restoration of some of the initial technical parameters of the battery [9].

The aim of this paper is to evaluate the performances of some aged lithium-polymer batteries employed in two electronic devices (a notebook and a tablet) after applying the reconditioning procedure.

\section{Materials and methods}

One tried to evaluate and recondition a couple of Li-polymer batteries employed in a power bank with two charging modes, namely solar and USB charging, a tablet and a notebook. Unfortunately, the

\footnotetext{
*email:di_vaireanu@yahoo.co.uk
} 
first battery, employed in a power bank with two charging modes, namely solar and USB charging was deformed, a swelling of the outer cast, being noticed due to the generation of gases from an electrochemical reaction occurring in the cell (Figure1.). Non-compliant exploitation of lithiumpolymer batteries may lead to physical deformation of the outer casing. Another cause that may lead to the occurrence of deformations is the way the charging stage of the batteries is realized, more precisely the charging directly from a power source without a professional charger. In Figure 1, an example of a battery with the deformed outer casing is represented.

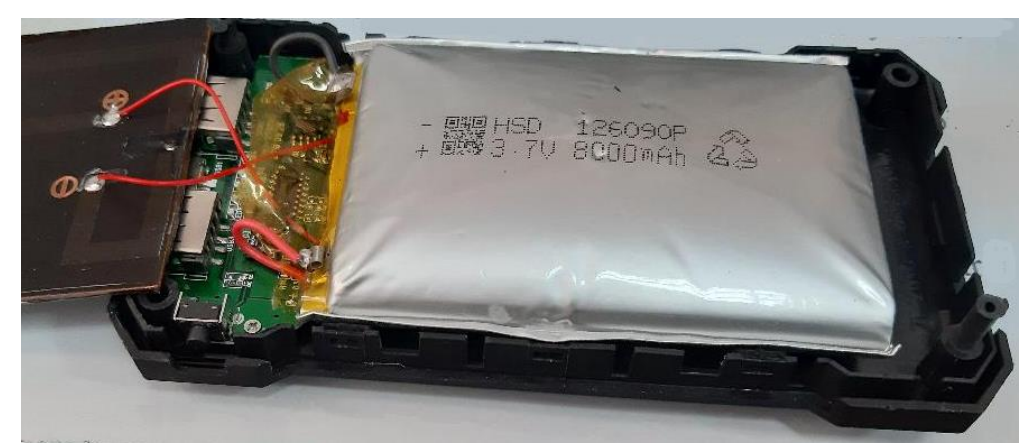

Figure 1. Image of the battery employed in a power bank with two charging modes, namely solar and USB charging

A case study carried out refers to the reconditioning of the lithium-polymer batteries that form the battery of a Dell Lattitude 13 Notebook. Initially, this battery was charged using the laptop charger, and when starting the laptop, a running time of 14 min was indicated. The battery was detached from the laptop and then in order to reach the constituent battery groups, the outer casing was removed.

The laptop battery was made of six lithium-polymer cells connected in three groups of two cells: each group contains two batteries mounted in parallel, and the groups are mounted in series. A basic diagram of the laptop battery is shown in Figure 2.

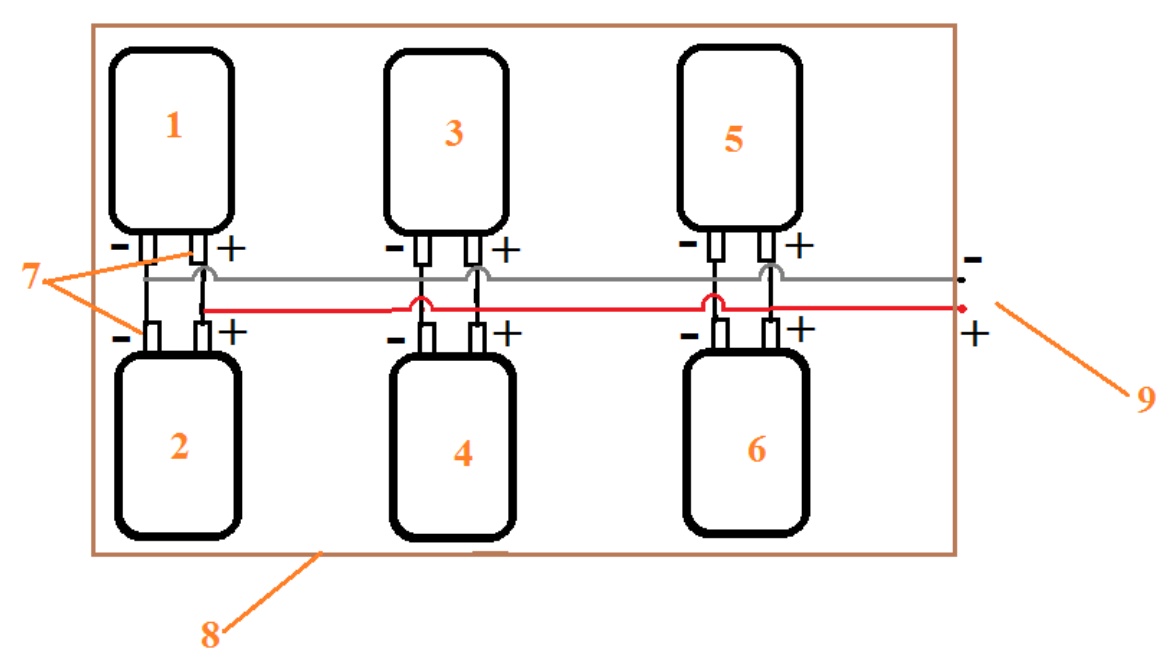

Figure 2. Principle diagram of the investigated notebook battery:

1-6 lithium-polymer batteries, 7 - battery terminals, 8 - battery case, 9 - frame

The placement of the batteries and the practical way of making connections for the reconditioning procedure are shown in Figure 3. 


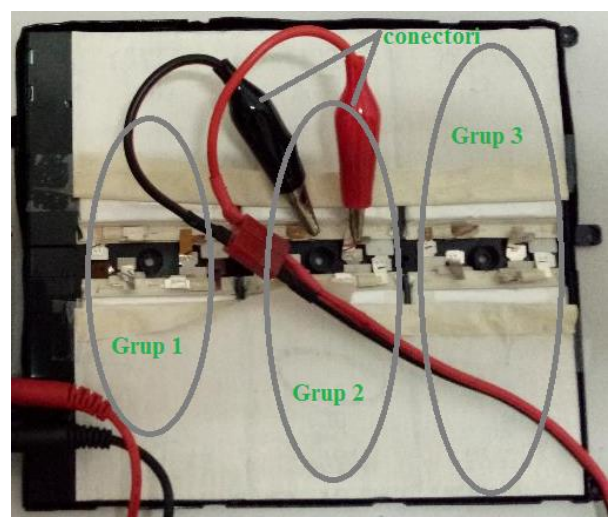

Figure 3. Placement of the

lithium-polymer batteries

in the studied battery

The procedure of reconditioning and evaluating the performance of the batteries was performed with a professional LiPro Balance Charger Imax B6 charger. This charger provides information on the charge / discharge capacity, battery voltage, charge / discharge time and charge / discharge current intensity.

The charging procedure of each individual group was performed independently at an initial charging current of $1.5 \mathrm{~A}$, until a voltage value of $4.2 \mathrm{~V}$ was reached, the first charging step, followed by a second charging step, when the applied value of voltage was kept constant at $4.2 \mathrm{~V}$ and the charging current decreased with increasing charging time, until a value of $10 \mathrm{~mA}$ was reached. The whole procedure was pre-programmed in the Professional Imax B6 charger. The discharge procedure for each group was performed at a constant discharge current of 1A. This step ended when the group voltage value reached $3 \mathrm{~V}$.

The internal battery resistance was measured using a dedicated 4 probe cell internal resistance meter (RIM 1000, Voltcraft, Germany). The measurement of the internal resistance was performed in groups of five replicated measurements, and the average resistance value of each group was calculated using these values.

The tablet battery was subjected to a similar reconditioning procedure. The technical specifications of the battery indicate a lithium-polymer battery with an initial nominal factory capacity of 5200mAh. One tried to charge the battery using the professional charger, but due to the overdischarged battery the charger refused to start the charging procedure indicating an error message.

This is a common situation often met in the cases of rechargeable batteries having a voltage below the limiting threshold value of $3 \mathrm{~V}$ set for the lower limit of the professional chargers (Figure 4).

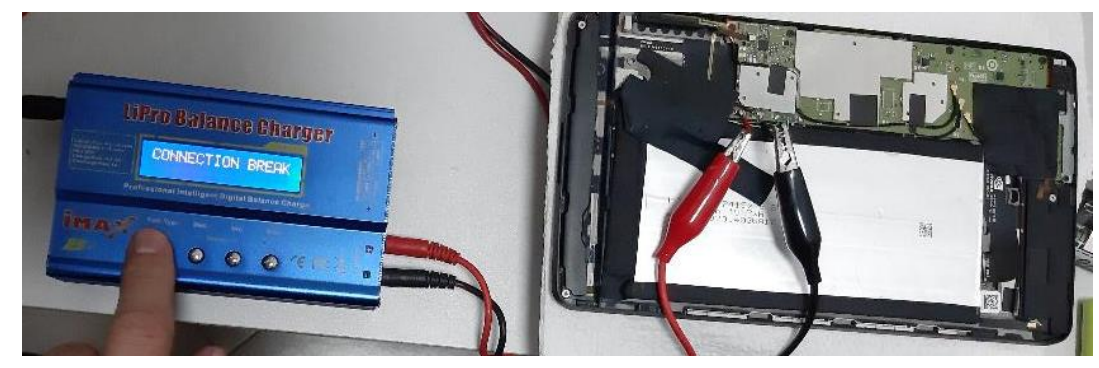

Figure 4. Experimental setup of a professional charger refusing the charging stage of a lithium-polymer battery

One may wonder how would be this possible when most of the cells have attached safety circuits preventing the cell overdischarge. The explanation for this is that once the limiting voltage is reached and the device is switched off automatically, and it is left for a certain period of time without recharging it, the discharge process continues due to a self-discharge stage, bringing the terminal cell voltage below $3 \mathrm{~V}$. 
A possible solution we envisage in order to solve this problem is to connect the device to an ordinary power source. However, this may get out of control, if the power supply is not provided with the option of constant current regime.

Another safer revitalization solution for batteries with terminal voltage below $3 \mathrm{~V}$ we would like to present is to put the overdischarged battery in parallel with another battery, of the same kind, lithiumion or lithium-polymer, having a terminal voltage above $3.7 \mathrm{~V}$, and this parallel system is subjected to a normal charging procedure. After a period of $5 \mathrm{~min}$, the terminal value for this system will reach a value above $3 \mathrm{~V}$, no matter how low is was the first cell terminal voltage, and one may now disconnect the auxiliary battery, leaving only the cell of interest connected to the charger. The battery is then discharged up to the value of $3 \mathrm{~V}$, recharged again, and this cycle is repeated 5 times.

The circuit built using a backup battery is presented in Figure 5.

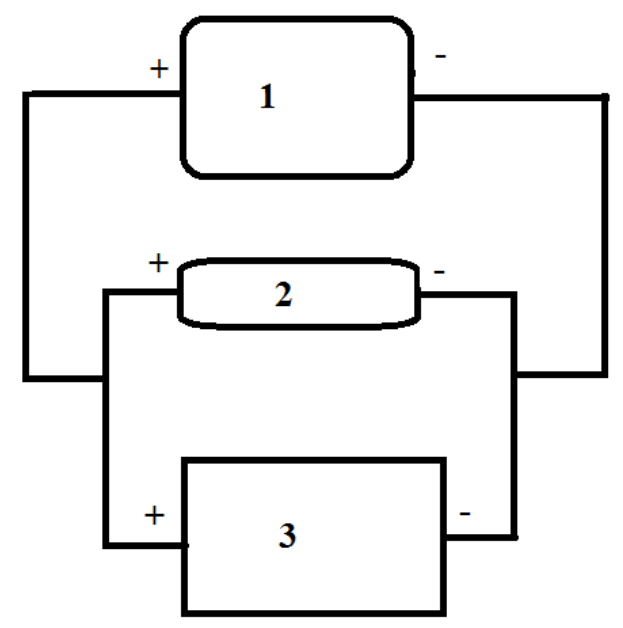

Figure 5. The experiment layout of the parallel connected batteries to overcome the drawback of an overdischarged battery:

1-power supply, 2 - backup battery , 3 - tested battery

The experimental setup for the reconditioning and evaluation of the lithium-polymer battery used in the tablet is shown in the Figure 6.

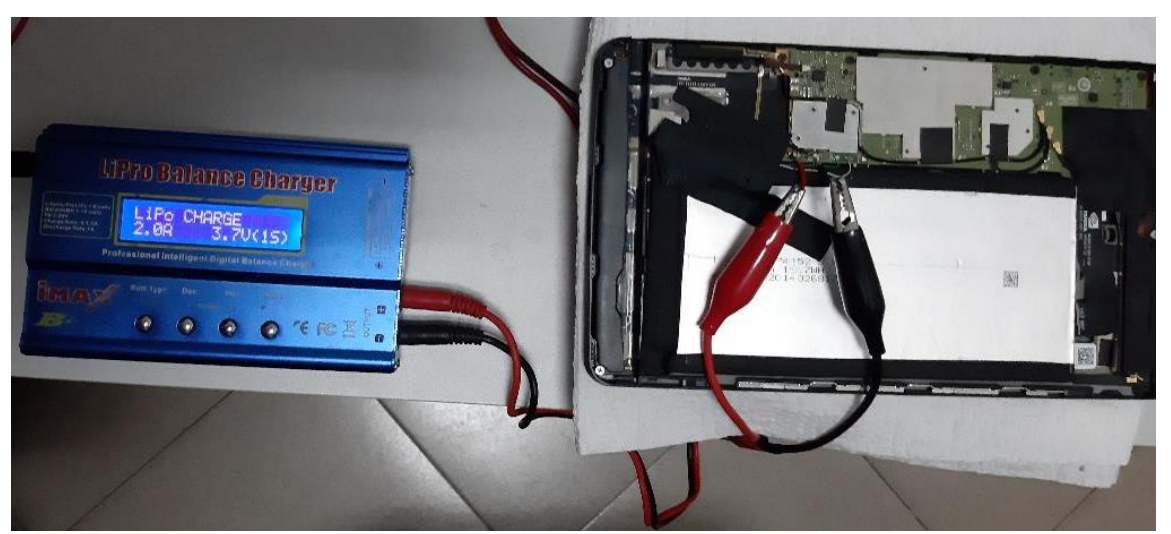

Figure 6. The experimental setup used to evaluate the lithium-polymer battery used in the investigated tablet

The tablet battery was subjected to the reconditioning procedure by carrying out 5 controlled charge/discharge cycles. For the charging cycle, one has set a $2 \mathrm{~A}$ charging current until the system 
registers a voltage value of $4.2 \mathrm{~V}$, and the discharge cycle was performed at a discharge current of $1 \mathrm{~A}$ until the system records a voltage value of $3 \mathrm{~V}$.

After the reconditioning procedure was applied, the battery was evaluated to determine the degree of reconditioning. The evaluation of the battery after the reconditioning procedure was performed in triplicate.

\section{Results and discussions}

\section{The reconditioning of a battery employed in Dell Lattitude 13 notebook}

In Table 1, one may find the measured values of the charge and discharge capacities for each group of lithium-polymer batteries existing in the battery of the investigated laptop are represented.

Table 1.The values of the charge capacity and the discharge capacity of the lithium-polymer battery groups

\begin{tabular}{|c|c|c|}
\hline Group of batteries & $\begin{array}{c}\text { Discharging capacity, } \\
\text { mAh }\end{array}$ & Charging capacity, mAh \\
\hline 1 & 1839 & 1922 \\
\hline 2 & 1637 & 1714 \\
\hline 3 & 1656 & 1703 \\
\hline
\end{tabular}

The technical specifications of the investigated battery allow the calculation of the initial capacity of the battery groups, using the energy (E) and the voltage (U) provided, as follows (equation 1):

$$
Q_{i}=\frac{E}{U}, A h
$$

Thus, the initial capacity of the battery groups providing $30 \mathrm{Wh}$ of power and $11.1 \mathrm{~V}$ voltage is 2702.7mAh.

After the reconditioning step, the capacity of the Li-polymer battery groups is (equation 2):

$$
Q_{r}=\frac{\sum_{i=1}^{3} Q_{i}}{3}=1710.7 \mathrm{mAh}
$$

Upon completion of the reconditioning procedure, the battery was charged and mounted in the laptop frame. When starting the laptop, a running time of two hours and nine minutes is observed.

The improvement of battery life may be calculated from the values of the battery operating times, more precisely as the ratio between the operating time before the reconditioning procedure and the operating time after applying the reconditioning procedure (equation 3 ):

$$
P=\frac{t_{i}}{t_{r}}
$$

Thus, for the tested battery a degree of improvement in the operating life of 9.2 times is obtained.

A parameter $\mathrm{k}_{\mathrm{r}}$, called the reconditioning coefficient, is defined as the ratio between the capacity of the accumulators after applying the reconditioning procedure and the initial capacity of the accumulators (equation 4).

Thus, for the three groups of batteries, the reconditioning coefficient has the value 0.633.

$$
k_{r}=\frac{Q_{r}}{Q_{i}}=\frac{1710.7}{2702.7}=0.633
$$

The most common expressions used for showing the improvements have the forms of percentage. The proposed coefficient may also be interpreted as a percentage form, namely, a value of the reconditioning coefficient of 0.633 is equivalent with a $63.3 \%$, value that shows the degree of recovery reported to the initial performances.

In Table 2, one may find the measured values of the internal resistance for the groups of batteries employed in the investigated laptops battery, the average values, the standard deviation and the relative standard deviation for each group. 
Table 2. The values of the internal resistance for the

investigated lithium-polymer battery groups

\begin{tabular}{|c|c|c|c|c|c|c|c|c|}
\hline $\begin{array}{c}\text { Group of } \\
\text { batteries }\end{array}$ & \multicolumn{5}{|c|}{ Internal resistance, $\mathbf{m} \boldsymbol{\Omega}$} & $\begin{array}{c}\text { Average resistance } \\
\mathbf{m} \boldsymbol{\Omega}\end{array}$ & $\begin{array}{c}\text { SD } \\
\text { RSD, } \\
\boldsymbol{\%}\end{array}$ \\
\hline 1 & 1394 & 1410 & 1408 & 1420 & 1407 & 1407.8 & 9.28 & 0.66 \\
\hline 2 & 1543 & 1474 & 1481 & 1519 & 1525 & 1506.0 & 26.74 & 1.78 \\
\hline 3 & 1441 & 1463 & 1487 & 1506 & 1511 & 1481.6 & 29.51 & 1.99 \\
\hline
\end{tabular}

Moreover, one has calculated the standard deviation and the relative standard deviation for the values of the internal resistance. One may see that the values of the relative standard deviation are below the $2 \%$ threshold, meaning that the reconditioning procedure brought the cells to a nearly identical value or the internal resistance, therefore the discharge stage is likely to occur uniformly with respect to each cell.

\section{The reconditioning of a battery employed in a tablet}

In Table 3, the values of the charging and discharging capacity for the battery employed in a commercially available tablet are presented. The capacity values represented in this table are the ones registered after the reconditioning procedure of the battery.

Table 3. The values of the charging and discharging capacities of the lithium-polymer battery employed in a tablet

\begin{tabular}{|c|c|c|}
\hline No. of determinations & $\begin{array}{c}\text { Discharging capacity, } \\
\text { mAh }\end{array}$ & Charging capacity, mAh \\
\hline 1 & 4578 & 4751 \\
\hline 2 & 4568 & 4830 \\
\hline 3 & 4512 & 4722 \\
\hline
\end{tabular}

By calculating the reconditioning coefficient of the tested battery with equation (4), one may see that the value of this coefficient is 0.88 . This coefficient indicates that after reconditioning, the battery operates at $88 \%$ of its initial performance. In Table 4, one may find the measured values of the internal resistance of the notebooks battery, the average of the internal resistance, the standard deviation and the relative standard deviation for the values of the internal resistance. One may see that the values of the relative standard deviation are close to the $2 \%$ threshold, similar to the above mentioned case.

Table 4. The values of the internal resistance for the investigated lithium-polymer battery

\begin{tabular}{|c|c|c|c|c|}
\hline $\begin{array}{c}\text { No. of } \\
\text { measurements }\end{array}$ & Internal resistance, $\mathbf{m} \boldsymbol{\Omega}$ & Average resistance, $\mathbf{m} \boldsymbol{\Omega}$ & $\mathbf{S D}, \mathbf{m} \boldsymbol{\Omega}$ & $\mathbf{R S D}, \boldsymbol{\%}$ \\
\hline 1 & 923 & & & \\
\hline 2 & 898 & & 10.01 & 1.1 \\
\hline 3 & 919 & & & \\
\hline 5 & 906 & & & \\
\hline
\end{tabular}

\section{Conclusions}

The two case studies regarding the application of a reconditioning procedure of aged lithiumpolymer batteries used in a notebook, and, respectively, a tablet showed that the proposed reconditioning procedure led to a successful revitalisation of the investigated batteries. The reconditioning procedure applied consists of charging/discharging steps at controlled current values. A novel quantification parameter was introduced, in order to decide whether or not the reconditioning procedure is successful, namely a reconditioning coefficient, $\mathrm{k}_{\mathrm{r}}$. The evaluation of the investigated batteries after the reconditioning procedure showed that one achieved a reconditioning coefficient above 0.6 , versus 1 when the battery was considered brand new. 


\section{References}

1. SERGI, F., ARISTA, A., AGNELlO, G., FERRARO, M., ANDALORO, L., ANTONUCCI, V., J. Energy Storage, 8, 2016, p. 235.

2. YUAN, Q.F., ZHAO, F., WANG, W., ZHAO., Y., LIANG, Z., YAN, D., Electrochim. Acta, 178, 2015, p. 682.

3. YU, Y., WANG, W., WANG, D., HUANG, K., WANG, L., BAO, L., WU, F., J. Hazard. Mater., 229-230, 2012, p. 455.

4. APPETECCHI, G.B., ALESSANDRINI, F., CAREWSKA, M., CARUSO, T., PROSINI, P.P., SCACCIA, S., PASSERINI, S., J. Power Sources, 97-98, 2001, p. 790.

5. SCROSATI, B., CROCE, F., PANERO, S., J. Power Sources, 100, 2001, p. 93.

6. BUGA, M., RIZOIU, A., BUBULINCA C., BADEA, S., BALAN, M., CIOCAN, A., CHITU, A., Rev. Chim., 69, (3), 2018, p. 549.

7. NATKUNARAJAH, N., SCHARF, M., SCHARF, P., Procedia CIRP, 29, 2015, p. 740.

8. UNTERREINER, L., JÜLCH, V., REITH, S., Eenrgy Procedia, 99, 2016, p. 229.

9. BENGA, F.M., VAIREANU, D.I., CIOBOTARU, I.A., CIOBOTARU, I.E., Rev. Chim., 69, (4), $2018,351$.

Manuscript received: 25.11 .2019 